Mem. Inst. Oswaldo Cruz, Rio de Janeiro, Vol. 78 (1) :83-94, jan./mar. 1983

\title{
FACTORS INFLUENCING THE DEVELOPMENT OF PLASINODIUM GALLINACEUM IN AEDES FLUVIATILIS
}

\author{
MARIANA V. TASÓN DE CAMARGO \\ ROTFAUT A. G. B. CÔNSOLI \\ PAUL WILLIAMS \\ ANTONIANA U. KRETTLI*
}

\begin{abstract}
Aedes fluviatilis is susceptible to infection by Plasmodium gallinaceum and is a convenient insect host for the malaria parasite in countries where Aedes aegypti cannot be maintained in laboratories. In South America, for instance, the rearing of A. aegypti the main vector of urban yellow fever, is not advisable because of the potential health hazard it represents. Our results of the comparative studies carried out between the sporogonic cycle produced with two lines of $\mathrm{P}$. gallinaceum parasites into $\mathrm{A}$. fluviatilis were as follows. As proved for A. aegy pti, mosquito infection rates were variable when A. fluviatilis blood-fed on chicks infected with an old syringe-passaged strain of $\mathrm{P}$. gallinaceum. Oocysts developed in $41 \%$ of those mosquitos and the mean peak of oocyst production was 56 per stomach. Salivary gland infections developed in about $6 \%$ of the mosquitos. The course of sporogony was unrelated to the size of the inoculum administered to chicks or to the route by which the birds were infected. The development of infected salivary glands was unrelated to oocyst production. Sporogony of $\mathbf{P}$. gallinaceum was more uniform when mosquitos blood-fed on chicks infected with a sporozoite-passaged strain. Oocysts developed in about $50 \%$ of those mosquitos and the mean peak of oocyst production was 138 per stomach, with some individuals having as many as 600-800 oocysts. Infected salivary glands developed in a mean of $27 \%$ of the mosquitos but, in some batches, was as high as $50 \%$. Patterns of salivary gland parasitism were similar to those of oocyst production. The course of sporogony of $\mathrm{P}$. gallinaceum in $\mathrm{A}$. fluviatilis is analized in relation to degree of parasitemia and gametocytemia in the vertebrate host.
\end{abstract}

Preliminary studies by Tasón de Camargo \& Krettli (1978) showed that Plasmodium gallinaceum undergoes sporogony in Aedes fluviatilis but that the proportion of mosquitos becoming infected is variable and unpredictable. Sporogony was usually high in mosquitos fed during the first days of malaria patency. The model $P$. gallinaceum in this species of mosquito should be well known and standardized because, under our condi-

Work supported by CNPq (P.D.E. 2222.8.019/80) Brazil.

Departamento de Parasitologia, Universidade Federal de Minas Gerais and Centro de Pesquisas René Rachou, FIOCRUZ, Caixa Postal 1743, 30000 Belo Horizonte, Minas Gerais, Brazil.

* To whom reprint requests and correspondence should be addressed at Av. Augusto de Lima, 1715 30000 Belo Horizon te, MG, Brazil.

Received for publication June, 9 th and accepted July 5 th, 1982. 
tions, it is an ideal invertebrate host to produce the sporogonic cycle of malaria parasites for didactic purposes as well as for research work with sporozoites. We attempted, therefore, to obtain more uniform infections in A. fluviatilis and more consistent rates of salivary gland parasitism. The possible influencing factors were examined; oocyst production in relation to the age of infection in chicks, to the inoculum size and route used to infect chicks; susceptibility of chicks to the sporozoites obtained from A. fluviatilis; and, the course of blood infection after parasites had been passaged through mosquitos as compared to the infection produced in the vertebrate host by an old syringe-passaged strain of $P$. gallinaceum.

\section{MATERIAL AND METHODS}

\section{$P$. gallinaceum}

The strain used initially for our work, named line $B$, was received in 1970 from the Instituto Oswaldo Cruz (Manguinhos, Rio de Janeiro) being originally sent to that Institute by Professor Brumpt (Galvão, 1945). The parasites have been maintained in our laboratory by syringe-passaged of infected blood, at 8 - to 10 - day intervale, through domestic fowls. During the present work, a line of parasites named "line S" was developed from sporozoites isolated from $A$. fluviatilis and maintained for no more than 3 sucessive blood passages before being again passaged through mosquitos. Inocula were made with blood collected in $3.8 \%$ Na citrate solution and calculated by counting erythrocytes $/ \mathrm{mm}^{s}$ and percent of parasitemia in Giemsa-stained blood smears. The birds used were hybrid chicks, 1-2 weeks old at the beginning of experiments and received $10^{5}-10^{9}$ infected erythrocytes each, in $0.2 \mathrm{ml}$, intravenously or intramuscularly. They were provided with ample water and starter ration. During cool days they were kept with an electric heater on.

\section{A. fluviatilis}

The mosquitos were of a laboratory colony established by Cônsoli (1976) from larvae and adults collected from natural breeding sites in and around the city of Belo Horizonte. Immature stages and adults were maintained in an environmental room at $27 \pm 1^{\circ} \mathrm{C}$, relative humidity $70-80 \%$. Mosquitos received $10 \%$ aqueous glucose solution except for the 12 hours before blood feeding. For infections they were confined in small containers made from paper cups, each holding 15.25 one-week-old females which had not been blood-fed previously. Usually $50-60 \%$, but sometimes $90 \%$ of the mosquitos fed in $30 \mathrm{~min}-1$ hour. Blood-fed females were transferred to clean containers, supplied with glucose solution, and kept in the environmental room until dissected on days 7-9 after blood meal.

\section{Sporozoite infections}

Chicks were bitten by experimentally infected mosquitos or injected with infected salivary glands. Sporozoite transfer from $A$. fluviatilis to chicks was made 7-14 days after the mosquitos ingested the infective blood meal.

\section{Assessment of parasitemia in chicks}

Parasitemia was determined in Giemsa-stained blood smears by examining 1,000 erythrocytes by oil-immersion objective. When mosquitos were to be fed on an infected chick, proportions of asexual forms and gametocytes were enumerated separately. A smear was considered negative when no parasites were found after examining 50 microscopic fields (about 5,000 erythrocytes).

\section{RESULTS}

SPOROGONY OF LINE $B$ PARASITES - Three groups of chicks were inoculated intramuscularly (i.m.) with $10^{5}, 10^{7}$ or $10^{9}$ parasitized red blood cells (PRBC) per 
bird. Between days 3-14 of chick infection lots of 10-15 mosquitos were blood-fed dally on them. At each day, parasitemia percent and gametocyts rates were determined in the chick's blood smears. The results of chick infections and of the sporogonic stages, i.e. oocysts in the migduts and sporozoites in the salivary glands in $A$. fluviatilis are illustrated in Fig. 1, being as follows.

Of the mosquitos fed on days 6-14 on chicks inoculated with $10^{5}$ PRBC $86 \%$ developed oocysts. The mean infection rate among those insects was 38 oocysts per stomach. Salivary gland sporozoites were found only in mosquitos $(37 \%)$ fed between days 6-9 of chick infection, when the gametocyte rate was $0.4-4.4 \%$.

Mosquitos fed on days 5-12 on chicks inoculated with $10^{7}$ PRBC developed oocysts ( $68 \%$ of them) when gametocyte rates rose from 0 to $6.5 \%$ and declined to $1.1 \%$. Peak production of 60 oocysts per stomach was found on mosquitos fed on day 6 of chick infection. Salivary gland sporozoites were found only in mosquitos (35\%) fed on days $5,6,8$ and 9 of chick infection when the gametocyte rate rose from $0.5 .4 \%$.

Mosquitos fed on days 3-7 on chicks inoculated with $10^{9}$ PRBC developed oocysts $(63 \%)$ when the gametocyte rate was $0.4 .15 \%$. A peak rate of 62 oocysts per stomach was found in insects fed on day 5 of chick infection. Salivary gland infections were found in $51 \%$ of the mosquitos.

In summary, the infectivity of $P$. gallinaceum gametocytes (line B) to A. fluviatilis was short living and variable independently on the inoculum size used to infect the chicks i.m. (Fig. 1). Best oocyst and sporozoite production were found when parasitemia was rising and before its peak.

Line $B$ parasites inoculated intravenously (i.v.) was also used for sporogony studies with $A$. fluviatilis (Table I). Chicks received $10^{8} \mathrm{PRBC}$ i.v. and were used to feed the insects soon after infection (day 0) until the day when the chick died (day 4). All mosquito groups developed oocysts and a peak production of 59 and 191 oocysts per stomach were found, respectively on day 3 (Experiment 1) and day 2 (Experiment 2) of chick infection. Salivary glands were found in about $20 \%$ of the infected batches. Best results were observed on mosquitos fed on days $2-3$ of chick infection. Therefore, the use of i.v. infection allowed an earlier use of the vertebrate host for the production of malaria sporogonic stages in $A$. fluviatilis.

INFECTIVITY OF SPOROZOITES TO CHICKS - Sporozoites from mosquitos fed 7-14 days previously were used for the chicks infections and belonged to line $B$. In one series of experiments, each of 22 chicks were inoculated i.m. with 1 or 2 pairs of positive salivary glands dissected from mosquitos. Fourteen of the birds survived to develop patent infections, after pre-patent periods of 7.11 days (mean of 8.2 days). Twelve of these chicks died $9-13$ days after inoculation and two developed a chronic infection. In a second series of experiments, 14 chicks were each bitten by 2 or 3 mosquitos presumed to have infected salivary glands. Seven birds survived to develop patent infections after pre-patent periods of 6-13 days (mean of 8.4 days). All infected chicks died 8.15 days after being bitten by the mosquitos.

These successful transmission experiments provided the basis for line $S$ of $P$. gallinaceum parasites described as follows.

COMPARISON OF SPOROGONY OF LINE $B$ AND LINE $S$ - For direct comparison of the development of these parasite lines in $A$. fluviatilis, the chicks used as sources of blood-meals were infected by syringe passage, being inoculated with $10^{7} \mathrm{PRBC}$ per bird (i.m.) with one or other of the lines. The two parasite lines produced different courses of infection in chicks but, because the studies were primarily concerned with comparison of sporogony, mention need be made only to differences in gametocyte rates. 
Inoculo of: $10^{5}$ PREC/chick $0--010^{7}$ PREC/chick $\longrightarrow 10^{\circ}$ PRBC/Chick $5 .-4$
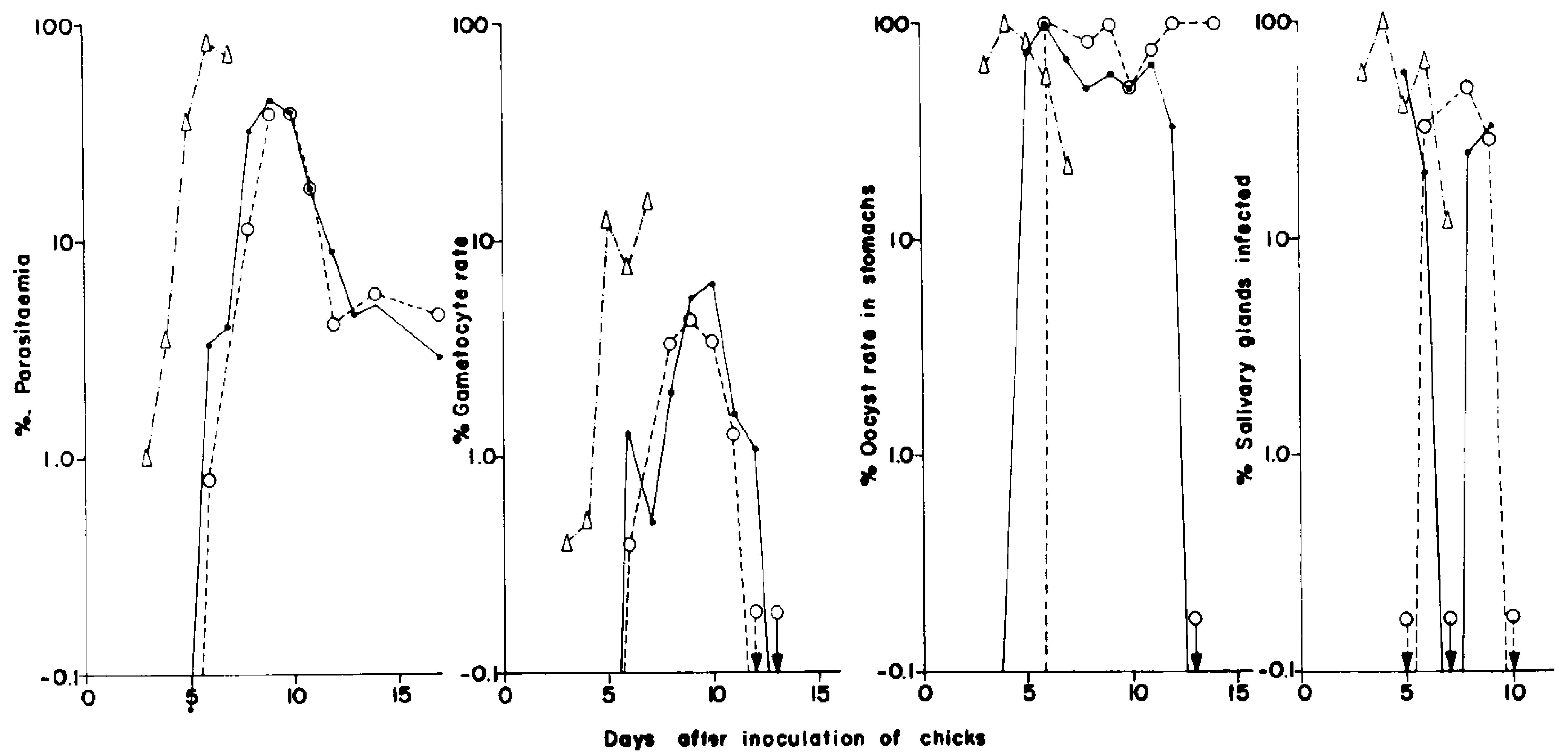

Fig. 1 - Sequences of development of Plasmodium gallinaceum line B in chicks and in Aedes fluviatilis: parasitemia and gametocy te rates in chicks; oocyst and salivary gland infection rates in mosquitos. 


\section{TABLE 1}

Infections of $A$. fluviatilis after feeding on chicks inoculated intravenously with $10^{8} P$. gallinaceum infected red blood cells. Results of two different experiments

\begin{tabular}{|c|c|c|c|c|c|c|c|c|c|c|}
\hline \multirow[b]{3}{*}{$\begin{array}{c}\text { Days } \\
\text { after } \\
\text { chick } \\
\text { inoculation }\end{array}$} & \multicolumn{5}{|c|}{ Experiment 1} & \multicolumn{5}{|c|}{ Experiment 2} \\
\hline & \multicolumn{2}{|c|}{ Infections in chicks } & \multicolumn{3}{|c|}{ Infections in mosquitos } & \multicolumn{2}{|c|}{ Infections in chicks } & \multicolumn{3}{|c|}{ Infections in mosquitos } \\
\hline & $\begin{array}{c}\text { Parasitemia } \\
\%\end{array}$ & $\begin{array}{c}\text { Gametocyte } \\
\text { rate } \\
\%\end{array}$ & $\begin{array}{l}\text { Stomachs } \\
\text { with } \\
\text { oocysts } \\
\text { Total } \\
\text { examined } \\
\text { (\%) }\end{array}$ & $\begin{array}{c}\text { Mean no. } \\
\text { oocysts } \\
\text { per } \\
\text { stomach }\end{array}$ & $\begin{array}{c}\text { Positive } \\
\text { salivary } \\
\text { glands } \\
\text { no. } \\
\text { examined } \\
\text { (\%) }\end{array}$ & $\begin{array}{c}\text { Parasitemia } \\
\%\end{array}$ & $\begin{array}{c}\text { Gametocyte } \\
\text { rate } \\
\%\end{array}$ & $\begin{array}{l}\text { Stomachs } \\
\text { with } \\
\text { oocysts/ } \\
\text { Total } \\
\text { examined } \\
\text { (\%) }\end{array}$ & $\begin{array}{l}\text { Mean no. } \\
\text { oocysts } \\
\text { ver } \\
\text { stomach }\end{array}$ & $\begin{array}{c}\text { Positive } \\
\text { salivary } \\
\text { glands/ } \\
\text { Total } \\
\text { examined } \\
\text { (\%) }\end{array}$ \\
\hline \multirow[t]{2}{*}{0} & 0.5 & 0 & $4 / 21$ & 1.3 & $0 / 20$ & 1.2 & 0.1 & $1 / 22$ & 3.0 & $0 / 20$ \\
\hline & & & $19 \%$ & & $0 \%$ & & & $4.5 \%$ & & $0 \%$ \\
\hline \multirow[t]{2}{*}{1} & 0.5 & 0.1 & $8 / 14$ & 4.2 & $2 / 13$ & 2.0 & 0.1 & $17 / 19$ & 17.5 & $4 / 17$ \\
\hline & & & $57 \%$ & & $15.4 \%$ & & & $89.5 \%$ & & $23.5 \%$ \\
\hline \multirow[t]{2}{*}{2} & 1.8 & 0.5 & $16 / 24$ & 16.1 & $3 / 21$ & 8.7 & 2.3 & $17 / 17$ & 191.0 & $3 / 13$ \\
\hline & & & $66 \%$ & & $14.3 \%$ & & & $100 \%$ & & $23 \%$ \\
\hline \multirow[t]{2}{*}{3} & 14.2 & 2.4 & $17 / 19$ & 59.3 & $5 / 18$ & 67.0 & 1.3 & $14 / 17$ & 37.0 & $3 / 14$ \\
\hline & & & $89 \%$ & & $28 \%$ & & & $82.3 \%$ & & $21 \%$ \\
\hline \multirow[t]{2}{*}{4} & 60.5 & 4.2 & $9 / 12$ & 27.0 & $1 / 11$ & 74.0 & 2.6 & $0 / 7$ & 0 & $0 / 7$ \\
\hline & & & $75 \%$ & & $9 \%$ & & & $0 \%$ & & $0 \%$ \\
\hline Total & - & - & $54 / 90(60 \%)$ & & $11 / 83(13 \%$ & & - & $49 / 82(60 \%$ & & $10 / 71(14 \%)$ \\
\hline
\end{tabular}



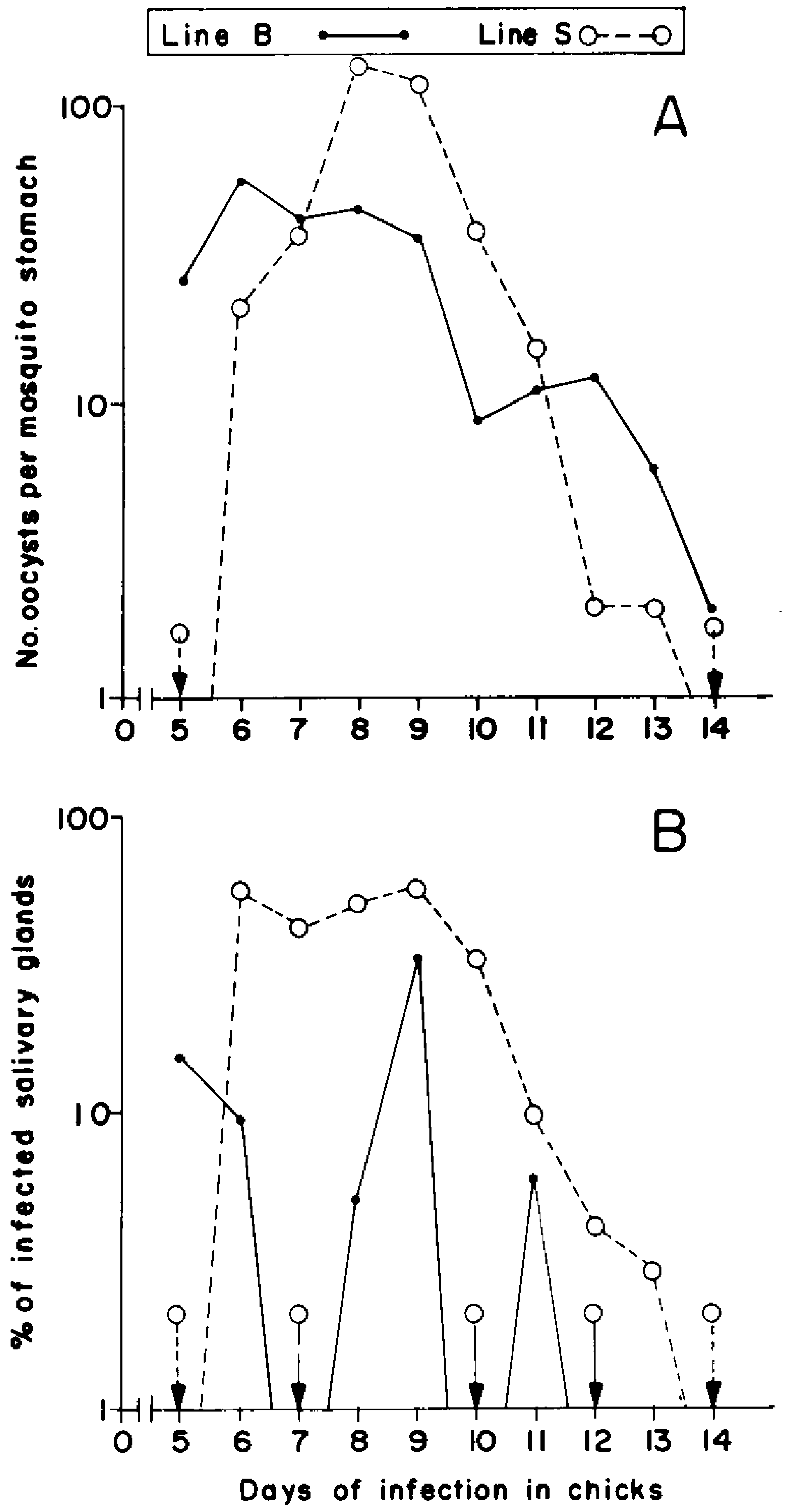

Fig. 2 - Production of oocyst in stomachs (A) and sporozoite in salivary glands (B) of mosquitos Aedes fluviatilis blood-fed in chicks at different times after inoculation of Plasmodium gallinaceum. respectively, line $B$, blood passaged only and line $S$ passaged through the vector before the blood transfer. 
In birds infected with line $B$, gametocytes were detected on days 5-18. The gametocyte rate rose from $0.05 \%$ (day 5) to 10.2 (day 10) and then declined. In birds infected with line $S$, gametocytes were recorded on days 7.13 of chick infection. The gametocyte rate rose from 0.7 (day 7) to a peak of 8.4 (day 9), then declined progressively. Inoculated chicks were not monitored after day 14 of infection.

Oocyst production by the two parasite lines in mosquitos $A$. fluviatilis is shown in Fig. 2. Of those fed on chicks infected with line $B$, oocysts were recorded in 127 of 309 dissected $(41 \%)$. The highest oocyst infection rate $(96 \%)$ and mean production (56 oocysts per stomach) was in mosquitos blood-fed on day 6 of chick infection when the average gametocyte rate was $0.9 \%$. Oocyst infection rates and intensities were high until day 9 , then decreased progressively. On day 15 of infection in chicks inoculated with line $B$, when the gametocyte rate was $0.9 \%$ (and equal to that leading to optimal oocyst production on day 6) infected mosquitos had on average only one oocyst per stomach. With line $S$ parasites, oocysts were found in $224(50 \%)$ of the 451 mosquitos dissected and fed on days $6-13$ of chick infection. The peak oocyst rate $(87 \%)$ and peak production (138 oocysts per stomach) occurred in mosquitos fed on days 8-9 when the gametocyte rate was $2.0 \%$. Some individual mosquitos developed $600-800$ oocysts.

The percentages of mosquito salivary glands infected with line $B$ is on Fig. 2B. Sixteen of the 258 specimens dissected $(6 \%)$ had sporozoites. A peak of $32 \%$ positive glands was found in mosquitos fed on day 9 of chick infection (gametocyte rate of $4.4 \%$ ). For line $B$, development of salivary gland infections in $A$. fluviatilis was usually irregular and unrelated to oocyst production. With line $S$, positive salivary glands were found in 100 of the 370 dissected specimens $(27 \%)$ and belonged to mosquitos fed on days 6-13 of chick infection. Positive gland rates of $57 \%, 42 \%, 50 \%, 57 \%$ and $33 \%$ were recorded in insects fed on days $6,7,8,9$ and 10 , of chick infection when the respective gametocyte rates were $0,0.7 \%, 2.0 \%, 8.4 \%$ and $3.0 \%$. Therefore, for this line of parasites, the development of salivary gland infections in $A$. fluviatilis was fairly uniform, and followed a pattern closely related to that of oocyst production.

DEVELOPMENTAL PATTERNS OF $P$. GALLINACEUM IN CHICKS AND IN A. FLUVIATILIS - Our experiments failed to produce evidence of a direct correlation between the course of blood infection in chicks and sporogony in the mosquitos. We found, however, that the two phases in the life cycle of $P$. gallinaceum are inversely related to one another when infections in both vertebrate and invertebrate hosts are related to the day of peak gametocyte production in chicks (Fig. 3). Furthermore, the oocyst production in A. fluviatilis was influenced by the line of parasite used and by the route of chicks inoculation. We analize in Fig. 4A the results of experiments in which chicks were infected with line $S$ by syringe passage i.m., and found that the peak oocyst production occurred in mosquitos fed on day -1 of the peak gametocyte rate. With line $B$ oocyst rates were lower and occurred in insects blood-fed at earlier of chick infection, i.e., on day -2 of the peak gametocyte rate in chicks inoculated i.v., and on day -4 for chicks inoculated i.m. The oocyst production rates in $A$. fluviatilis was related to the day of peak gametocyte rates but also to the \% gametocyte rates in chicks on the days immediately preceeding and succeeding the peaks of gametocytaemia (Fig. 4B). For mosquitos fed on chicks inoculated i.m. with line $B$, optimal oocyst production occurred in insects fed in chicks on day -5 of peak gametocyte; was minimal at the peak of gametocytaemia but slightly improved when mosquitos blood-fed in the later stages of chick infection. When $A$. fluviatilis fed on chicks inoculated i.v. with line $B$, the peak oocyst production occurred in insects that fed 3 days before the peak of gametocytaemia.

The proportion of infected salivary glands in relation to gametocytaemia is also analized in Fig. 4C. The highest rates of positive salivary gland infections were recorded in insects fed 3-5 days prior to the peak of gametocyte rate in chicks inoculated with line $B$. Parasites ingested by mosquitos fed after the peak of gametocytaemia were incapable 


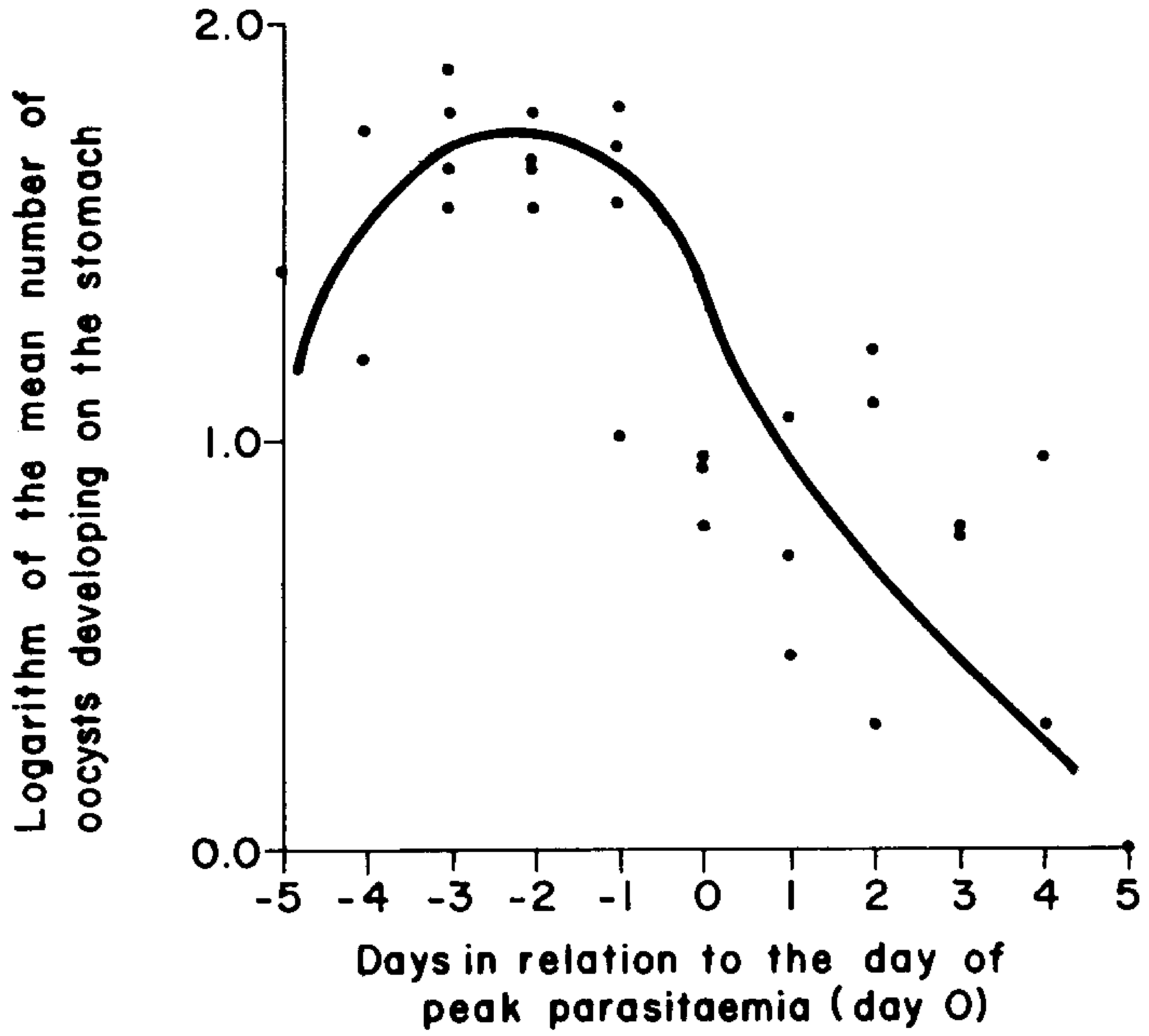

Fig. 3 - Comparison between rates of gametocyte formation in chicks and number of oocysts developing in $A$. fluviatilis stomachs as a function of day of the infective blood meal before and after peak parasitaemia.

of completing the sporogonic cycle. Mosquitos fed on chicks infected with line $S$ had the peak of positive salivary glands when fed 2 days before the peak gametocyte rate. Gametocytes of line $S$ ingested by Aedes in later stages of chick infection remained capable to complete the sporogonic cycle.

\section{DISCUSSION}

As one of the measures to prevent outbreaks of urban yellow fever, laboratory colonies of $A$. aegypti cannot be maintained in Latin American countries. For laboratories using $P$. gallinaceum as a tool for malaria studies, it has been necessary to find other invertebrate hosts that can be as useful and as easily reared as $A$. aegypti. Thus, although our studies might be of little interest to research workers in areas where yellow fever is not a problem, our observations are relevant for tropical American countries besides Brazil.

A. fluviatilis escaping from the laboratory when infected with $P$. gallinaceum could create difficulties for local poultry rearers. This is unlikely because the mosquitos 


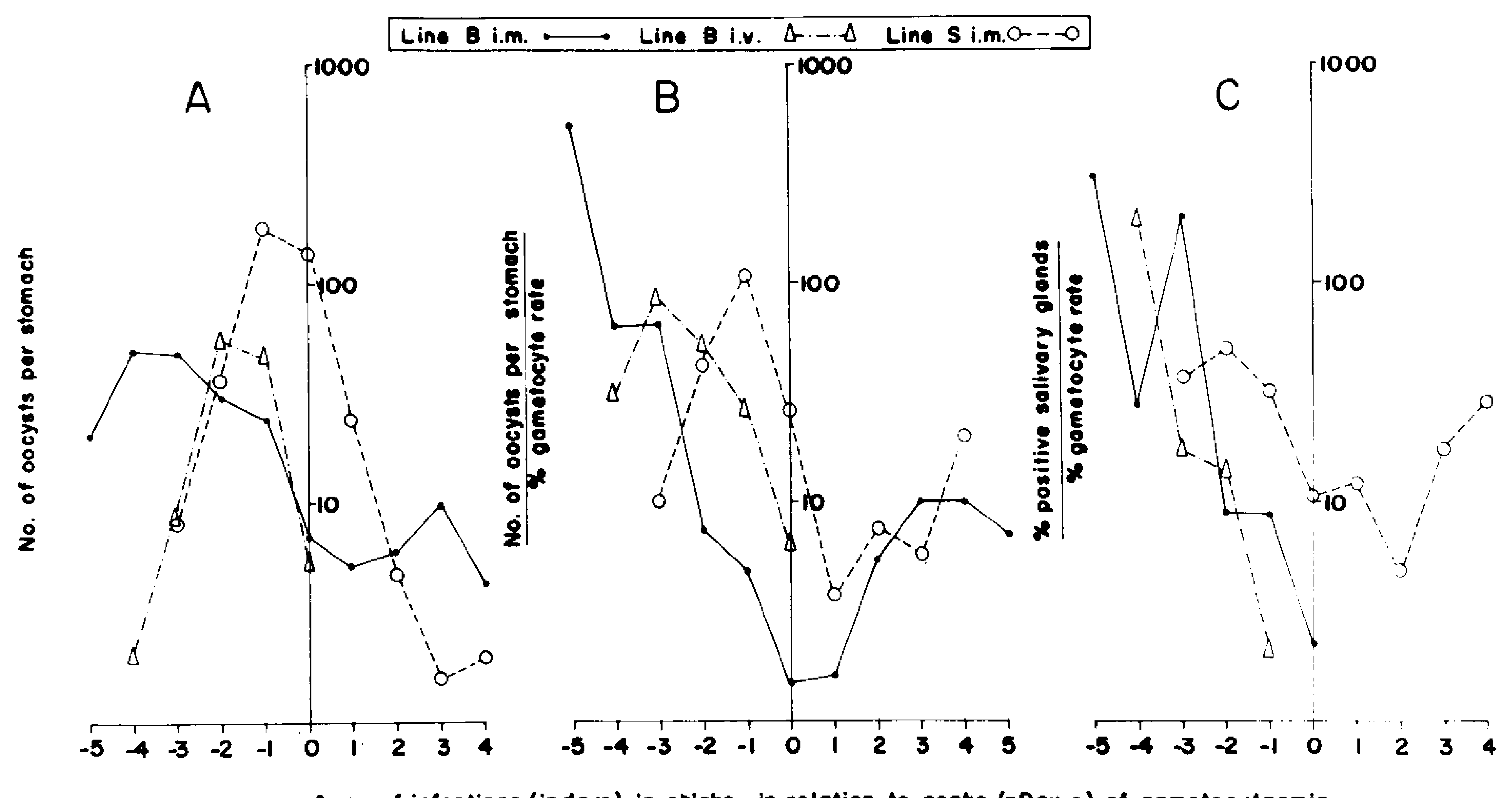

Ages of infections (indoys) in enicks, in relotion to peoks (- Doy o) of gamefocytaemia

Fig. 4 - Sequences of sporogony of Plosmodium gallinaceum in Aedes fluviatilis in relation to peaks of gametocy temia in chick blood: A - oocyst rates; B - oocyst rates as a function of \% gametocy temia in chicks; $\mathrm{C}$ - proportional salivary gland infection rates as a function of $\%$ gametocytemia in chicks. 
are strongly anthropophilic and reluctantly feed on chicks (Cônsoli, 1976; Cônsoli \& Williams, 1978). Best blood-feeding results were only obtained in the present investigation by adopting the artifice of holding mosquitos in small cages and starving them before the blood meal.

The fact that $A$. fluviatilis is susceptible to infection by $P$. gallinaceum is neither remarkable nor surprizing since the parasite is known to undergo sporogony in at least 25 species of Aedes and also in mosquitos of the genera Anopheles, Armigeres, Culex, Culiseta and Mansonia (Gamham, 1966). The sequence of events depicted here is closely similar to observations on the sporogony of $P$. gallinaceum in other species of mosquitos (Garnham, 1966; Huff \& Marchbank, 1955). Even though we used a heterogenetic stock of $A$. fluviatilis in our experiments the results are sufficient to conclude that $A$. fluviatilis is as efficient as $A$. aegypti to serve as a laboratory model to study factors influencing the sporogonic cycle of $P$. gallinaceum. By selective breeding of the $A$. fluviatilis stock, it should be possible to develop characterized lines of mosquitos so that direct comparison can be made between the behavior of $P$. gallinaceum in this mosquito and in, for example, selected susceptible pure strains of $A$. aegypti.

As in previous studies on the sporogony of $P$. gallinaceum (Eyles, 1951; Huff \& Marchbank, 1955) we could not establish a direct relationship between the course of infection in chicks and the subsequent development of the parasites in mosquitos. In previous studies, vector potential of a mosquito species was determined by comparisons between rates of over-all parasitemia in the vertebrate hosts and the development of oocysts on the stomach walls of the invertebrate hosts. However, the sporogony of every malaria parasite depends on the proportion of gametocytes capable not only of development to the oocyst stage but also of production of salivary gland infections. Therefore, it seems more realistic to relate the course of infection in mosquitos to the times of peak gametocytemia. The course of infection in mosquitos clearly depends on the way in which chicks are inoculated with $P$. gallinaceum and on the passage of parasites through an invertebrate host (Fig. 4). Successful maintenance of $P$. gallinaceum through $A$. fluviatilis is best obtained when the mosquitos blood-feed in an early patent period of infection in the vertebrate host, when parasitemia is rising.

Susceptibility of mosquitos to malaria parasites is influenced by characteristics inherent in the invertebrate (Kilama, 1973; Savage et al, 1971; Weathersby, 1952; Terzian, Stahler \& Irreverre, 1956) and also to factors deriving from the vertebrate. Inhibition or suppression of the transformation of gametocytes to gametes to allow the oocysts development in the invertebrate host is considered to be the result of adverse humoral antibodies (Behin, 1968; Carter \& Chen, 1976; Gwadz, 1976; Mendis \& Targett, 1981 ) or the accumulation of toxic by-products in the blood stream of the vertebrate host (Hawking, Worms \& Gammage, 1968; Huff, Marchbank \& Shiroishi, 1958). This concept is in general herein supported by correlating sporogony to the days of peak gametocyte production (Fig. 4).

Is has been suggested by Eyles (1951) that $A$. aegypti is more susceptible to infection by gametocytes of sporozoite-induced infections than to those of blood-induced infections. However, the author did not directly compare infectivity of sporozoite and blood-derived gametocytes relating his observations on sporozoite-induced infections. Herein, we describe minor differences in percent of $A$. fluviatilis that developed oocysts when fed in chicks with the lines $B$ (blood passage) and $S$ (sporozoite passage) of $P$. gallinaceum. However, at peak oocyst production, the number of oocysts were about 2.5 times greater in mosquitos exposed to line $S$ than in those exposed to line $B$. Corroborating such a difference, while an overall of $27 \%$ os mosquitos infected with line $S$ developed positive gland infections, only in $6 \%$ of those infected with line $B$ sporozoites were found in the salivary glands. The major difference between the two lines was the production of sporozoites in salivary glands which was fairly uniform with line $S$ but rather erratic and unpredictable with line $B . P$. gallinaceum lines derived from sporozoite- 
induced infection are therefore preferable when aiming at the production of sporozoites on a regular basis.

\section{RESUMO}

Aedes fluviatilis é susceptivel à infecção por Plasmodium gallinaceum, sendo considerado um modelo experimental útil para esta infeç̧ão em regiões nas quais Aedes aegypti não deve ser criado em laboratório, por razões de segurança. Na América do Sul, por exemplo, o A. aegypti é o principal vetor da febre amarela urbana não sendo aconsethável sua criação no laboratório pelo perigo que a espécie pode representar caso escapem exemplares do laboratório. Similarmente ao que ocorre com A. aegypti, as taxas de infecção do $A$. fluviatilis foram variáveis, quando utilizada uma cepa de $P$. gallinaceum mantida no laboratório por longo tempo através de passagens sangüíneas (linhagem $B$ ). Nesses mosquitos, desenvolveram-se oocistos em $47-63 \%$, havendo infecção das glândulas salivares em cerca de $15 \%$. O curso da esporogonia foi independente da dose do inóculo ou da via de administraçāo às aves. Também a infecção das glândulas salivares com a linhagem $B$ não dependeu do número de oocistos presentes no estômago. A esporogonia mostrouse mais uniforme quando os mosquitos $A$. fluviatilis sugaram pintos infectados com uma linhagem reisolada a partir de esporozoítas $(S)$. Cerca de $50 \%$ destes mosquitos desenvolverarr oocistos, havendo indivíduos com até 600 a 800 oocistos por estômago. A infecção média das glândulas salivares com a linhagem $S$ foi de $27 \%$, chegando a $57 \%$ em alguns grupos. Os padrōes do parasitismo das glândulas salivares foram semelhantes àqueles da produção de oocistos. O decurso da esporogonia de $P$. gallinaceum em $A$. fluviatilis foi analisada em relação aos índices de parasitemia e de gametocitemia no hospedeiro vertebrado.

\section{REFERENCES}

BEHIN, R., 1968. The influence of chicken serum proteins on the infection of Aedes aegypti with Plasmodium gallinaceum. Am. J. Trop. Med. Hyg., $17: 457-460$.

CARTER, R. \& CHFN, D.H., 1976. Malaria transmission blocked by immunization with gametes of the malaria parasite. Noture (London), $263: 57-60$.

CÔNSOLI, R.A.G.B., 1976. Estudos sobre a biologia do Aedes (Finlaya) fluviatilis (Lutz, 1904) em laboratório. Tese de Mestrado, Departamento de Parasitologia do Instituto de Ciências Biológicas da Universidade Federal de Minas Gerais, $110 \mathrm{pp}$.

CÔNSOLI, R.A.G.B. \& WILLlAMS, P., 1978. Laboratory observations on the bionomics of Aedes fluviatilis (Lutz) (Diptera: Culicidae). Bull. Entomol. Res., 68 :123-136.

EYLES, D.E., 1951. Studies on Plasmodium gallinaceum. I - Characteristics of the mosquito Aedes aegypti. Am. J. Hyg., 56 .101-112.

GALVÃO, A.L.A., 1945. Trabalhos da equipe de malária dos fundos universitários de pesquisa durante 1943-1944. Rev. Clin. S. Paulo. $17: 137-210$.

GARNHAM, P.C.C.. 1966. Malaria Parasites and other Haemosporidia. Oxford, Blackwell Scientific Publications, $1114 \mathrm{pp}$.

GWADZ, R.W., 1976. Malaria: Successful immunization against the sexual stages of Plasmodium gallinaceum. Science, $193: 1150-1151$.

HAWKING, F.; WORMS, M.J. \& GAMMAGE, K., 1968. 24 and 48 hour cycle of malaria parasites in the blood; their purpose, production and control. Trans. R. Soc. Trop. Med. Hyg., 62 :731-760.

HUFF, C.G. \& MARCHBANK, D.F., 1955. Changes in infectiousness of malarial gametocy tes. I Patterns of oocyst production in seven host parasite combinations. Exp. Parasitol, $4: 256-270$. 
HUFF, C.G.; MARCHBANK, D.F. \& SHIROISHI, T., 1958. Changes in infectiousness of malarial gametocy tes. II - Analysis of the possible causative factors. Exp. Parasitol, 7 .399-417.

KILAMA, W.L., 1974. Distribution of a gene for susceptibility of Plasmodium gallinaceum. J. Parasitol., $59: 920-924$.

MENDIS, K.N. \& TARGET, G.A.T., 1981. Immunization to produce a transmission-blocking immunity in Plosmodium yoelii malaria infections. Trans. R. Soc. Trop. Med. Hyg., $75: 158-159$.

SAVAGE, K.E., LOWE, R.E.; HAZARD, E.L. \& LOFGREN, C.S., 1971. Studies on the transmission of Plasmodium gallinaceum by Anopheles quadrimaculatus infected with a Nosema sp. Bull. WHO $45: 845-847$.

TASON DE CAMARGO, M.V. \& KRETTLI, A.U., 1978. Aedes fluviatilis (Lutz) : a new experimental host for Plasmodium gallinaceum Brumpt. J. Parasitol, 64 :924-925.

TERZIAN, L.A.; STAHLER, N. \& IRREVERRE, F., 1956. The effects of aging and modifications on the immunity of mosquitoes to malarial infection. J. Immunol., $76: 308-313$.

WEATHERSBY, A.B., 1952. The role of the stomach wall in the exogenous development of Plasmodium gallinaceum as studied by means of haemocoel injections of susceptible and refractory mosquitoes. J. Infec. Dis., $91: 198-205$. 